\title{
3D MODELLING AND MEDIEVAL LIGHTING RECONSTRUCTION FOR RUPESTRIAN CHURCHES
}

\author{
P. Lassandro ${ }^{1}$, M. Lepore ${ }^{1}$, A. Paribeni ${ }^{2}$, M. Zonno ${ }^{1}$ \\ ${ }^{1}$ Construction Technologies Institute, ITC - CNR, Bari Branch, Italy - (plassandro, mzonno, lepore)@itc.cnr.it \\ ${ }^{2}$ Università degli Studi di Urbino - DISTUM - andrea.paribeni@uniurb.it
}

\section{Commission II}

KEY WORDS: Laser scanning, Photogrammetry, 3D Modelling, Lighting analysis, Historical reconstruction.

\begin{abstract}
:
The aim of this research is to define a method, able to analyse the systems of illumination in the medieval period, through a 3D virtual model reconstruction. It specifically needs to deepen the interactions between natural and artificial illumination in confined spaces. The study describes and examines the best survey technique to obtain a 3D model reconstruction, according to the achievement of such lighting scenarios, and the most suitable tools for lighting analysis. Thus, it is possible to carry out accurate interpretations of the past starting from historical sources and scientific data about lighting. This method was validated on a case study of a rupestrian church in Matera. The rupestrian contexts are less investigated in relation to mediaeval artificial lighting even if there are recognitions and comparative studies of widespread contexts, not only in Puglia and Basilicata, but also in Mediterranean area (e.g. in Cappadocia and Cyprus) which allow identifying evidences related to artificial lighting systems. The architectural signs (hole, niches, etc.) for ancient luminaries can be studied in 3D and lighting prospective. Lastly, the virtual model of the rupestrian church was imported into an opensource visualisation software (3D Heritage Online Presenter) to be appreciable on line and to promote historical heritage knowledge.
\end{abstract}

\section{INTRODUCTION AND LITERATURE}

The researches on lighting systems in the past have often been carried out without considering the scientific aspects of light in detail (Melendo et al., 2018; Akca, 2012).

Therefore, a key aspect is the definition of an integrated method that makes possible to analyse the systems of illumination in the medieval period starting from historical studies, through a 3D virtual model reconstruction with a particular focus on the interactions between natural and artificial illumination in confined spaces.

The architectonic and material features of an artefact provide particular lighting effect and perceptions that can be re-created virtually taking into account the historical and scientific data.

Firstly, the study describes and examines the best survey technique to obtain a 3D model reconstruction, according to the achievement of such lighting scenarios. The choice of the most useful technology is affected both by the type of study to carry out and by the shape of the architectural artefact.

Over the years, it has been consolidated on the one hand the ability of the laser scanner to perform geometrically very precise surveys, on the other hand the ability of photogrammetry to generate very realistic textures.

This research has allowed evaluating the use of 3D acquisition and modelling techniques for lighting studies applied to historical heritage

In particular, it was considered both formal and material characteristics and lighting physical quantities.

Through this comparison, it was highlighted that the used survey techniques have advantages and disadvantages, which make them more suitable or less suitable according to the analysis of indoor lighting to perform.

This method was validated on a case study.
Thus, it was necessary to identify an artefact of cultural heritage with specific characteristics:

1. A built and not ruined artefact with no alterations in order to preserve original spaces and to be able to reconstruct the original lighting scenarios;

2. An artefact where it is possible to recognize signs and architectural elements that indicate the presence of luminaries, such as lamps or chandeliers;

3. An artefact with controlled natural lighting conditions in order to study lighting scenarios with the contribution of artificial light.

The rupestrian churches have such characteristics because natural light comes exclusively from the entrance in many cases. Considering that the intensity of lighting decreases rapidly as far from the light source, most of the spaces in the rupestrian churches are almost dark. Therefore, the main source of lighting is the artificial one, which, in the medieval period, was a lighting system with flame (oil lamps, chandelier etc.).

Regarding the illumination in the ancient world with flame, some multidisciplinary studies analysed daylight and artificial related to residential (Moullou et al., 2012; Moullou et al., 2010) and burial contexts buildings of the Roman and Greek age (Papadopoulos and Earl, 2009; Santucci et al., 2018,). In this research, the method was defined for the application to a religious artefact with complex and irregular spatiality, the rupestrian Santa Barbara's Church in Matera (south Italy), with wall paintings and in reference to recent historical studies of the middle ages.

Indeed, the research on lighting systems, both natural and artificial, used in medieval churches has marked remarkable progress in recent years.

Due to the copious available documentation, a greater interest was reserved for the monuments of the IV-VI centuries (baptistery of the Orthodox in Ravenna, S. Sofia in 
Constantinople), while the field of the rupestrian churches, which pose specific problems, is less investigated.

Our knowledge of early Christian church lighting system is very rich thanks to a rich tradition of literary sources and to a large amount of archaeological discoveries. Among the ancient texts that describe the lighting devices, a place of honour has to be deserved to the Ekphrasis of Paul Silentarios, composed for the second inauguration of Saint Sophia at Constantinople in 563. In this long and elaborate poem, Paul describes the artificial illumination as the effect of "a kind of nocturnal sun that filled the majestic temple with light". He continues praising the silver lamps in the shape of discs, vessels and crosses that, attached to long twisted chains of beaten brass stretched from the marble cornice of the dome, "float in a circle above the heads of men... providing them of a pendant source of light". The different shapes of precious lighting furniture described in the Ekphrasis are confirmed by some exceptional discoveries of ecclesiastical treasures such as those of Kumluca, in south-western part of Asia Minor (Bouras and Parani, 2008)

Compared to that of the early Christian period, the panorama of our knowledge of the matter for the middle byzantine centuries is very meagre indeed: the reduced scale of the churches built from the ninth century surely involved a remodelling of the variety and quantity of light sources employed for the liturgy. In this period, however, lighting continued to have a relevant role for the liturgy and, therefore, constituted a substantial item of expenditure, as the canonical acts and endowments regulating the destination of church revenues for keeping up the maintenance of light clearly show.

Buildings and liturgical spaces with a poor natural illumination, as rock-hewn churches that were very widespread in South Italy, Central Anatolia and Aegean and Mediterranean isles, posed peculiar problems.

Studies concerning the lighting system in this kind of churches are not very developed but, in order to visualize the typology of lamps employed and their distribution in the church space, some clues are offered for example by the so called Enkleistra of St Neophytos near Paphos (Cyprus). In this 12th century sanctuary, where the hermit Neophytos lived, is still possible to see holes drilled into the ceiling and brackets inserted into the walls for housing hooks to hold hanging simple or multi-nozzled lamps; moreover the presence of niches carved into the walls, blackened by the smoke, reveal the installation of lamps once there. This kind of material clues, together with the information offered by written documents - as monastic regulations and wills - and iconographic sources - paintings and miniatures with liturgical scenes - could provide a clearer picture of the lighting system in middle age rock hewn churches.

\subsection{Applied methodology and case study}

The work focuses on the Santa Barbara's Church in Matera (south Italy), which was built during the Byzantine period (10th11 th century $\mathrm{AD}$ ).

The Church is located in the Sassi of Matera. It is composed of a trapezoidal room, used by churchgoers, and the "bema", reserved for clergy. On the side walls of the central hall there are the Angevin paintings representing Santa Barbara (XV - XVI century), some of them in excellent condition.

The Church was built in a deep ravine (gravina) according to a northeast-southwest axis due to topographic reasons. The entrance is placed on the northeast side, in line with the apse. It is the only opening, in the geometry of the artefact, which conveys direct natural light into the church only during the early hours of the morning.

For the survey campaign, it was necessary to study a specific artificial lighting system able to illuminate the entire surface in a uniform manner, reducing the shadows. This was possible only with a complete control of artificial lighting, creating and setting up the photographic studio with spotlights and extendable rods. Considering that natural lighting was not enough to light up all the church until apse, it was preferable to prevent access to natural light closing the door.

Furthermore, it would have been very difficult to homogenize the incoming natural light, also because during the day it varies continually. The correct artificial lighting, which removed the shadows, various reflections and unwanted effects, allowed improving texture quality in relation to the stone and paintings features.

The project aim was to evaluate the results produced using photogrammetry and laser scanning techniques and possible combination for lighting analysis.

It was necessary to go on in an experimental way, analysing the problems and the available methodologies, in order to identify the most appropriate methodology.

The survey was performed with a laser scanner, because it was necessary to obtain a model with a more precise geometry, and with digital photogrammetry, to obtain a high resolution photorealistic texture (Merlo et al., 2013). The point clouds resulting from the scans were acquired with the Riegl VZ400 laser scanner (Figure 1).

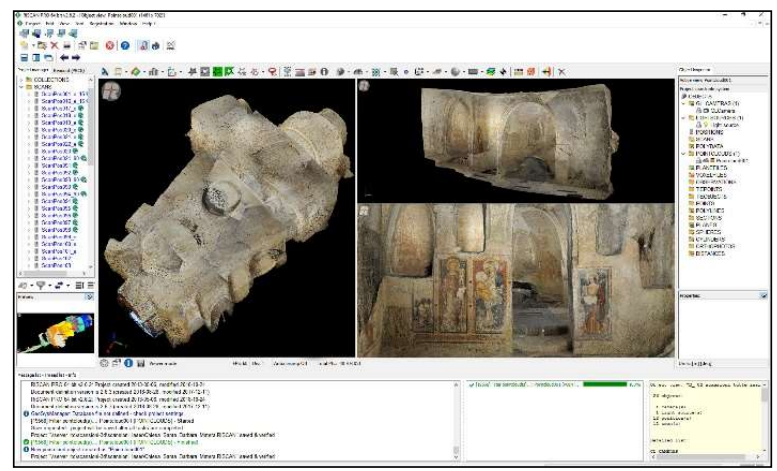

Figure 1: Sw RiscanPro. Point cloud model by laser scannings.

The mesh was created and managed with the Geomagic Wrap software for post-processing data (Figure 2).

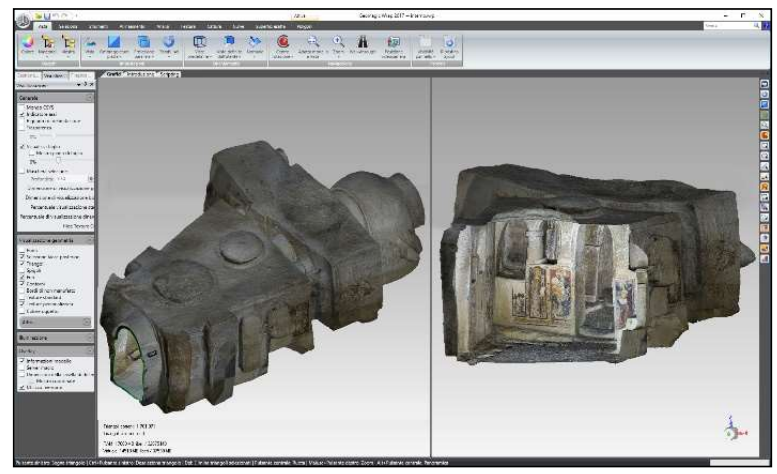

Figure 2: Sw Geomagic Wrap. Mesh model. 
The images for the realization of the model were acquired with 3DEYE and processed with the Agisoft Photoscan software (Figure 3, 4).

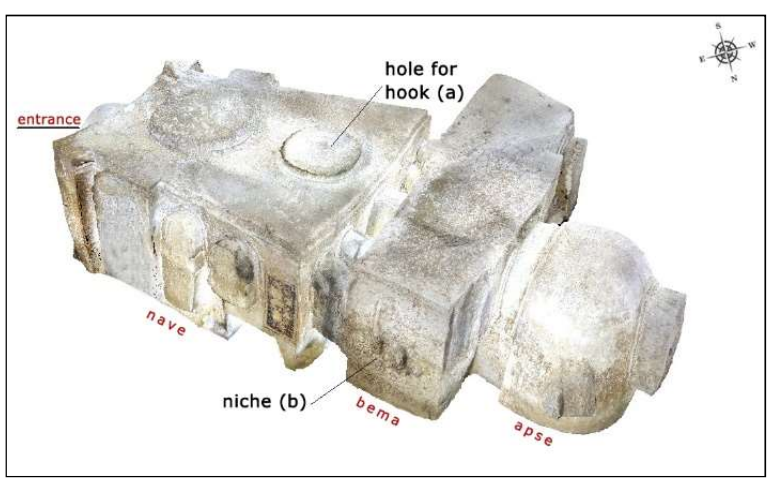

Figure 3: Agisoft Photoscan Sw. Texturing model.

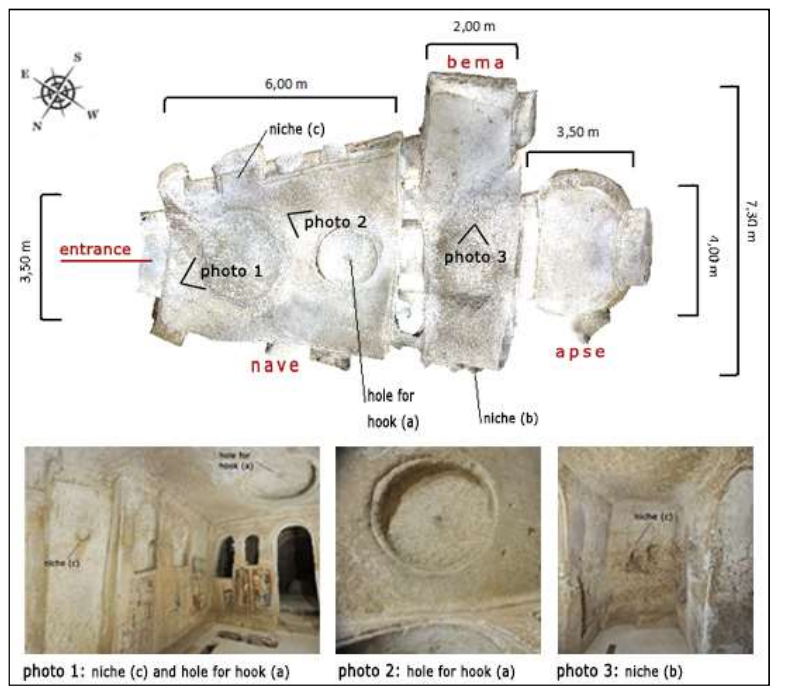

Figure 4: Agisoft Photoscan Sw. View of texturing model with the indications about niches and hole for hook.

The next step was to import the model in 3D studio Max (Figure 5 ) in order to perform quantitative and qualitative studies of indoor lighting. The obtained model is so ready to the analysis of lighting scenarios because quality and lighting effect depend on the artefact geometry and the characteristics of its surfaces.

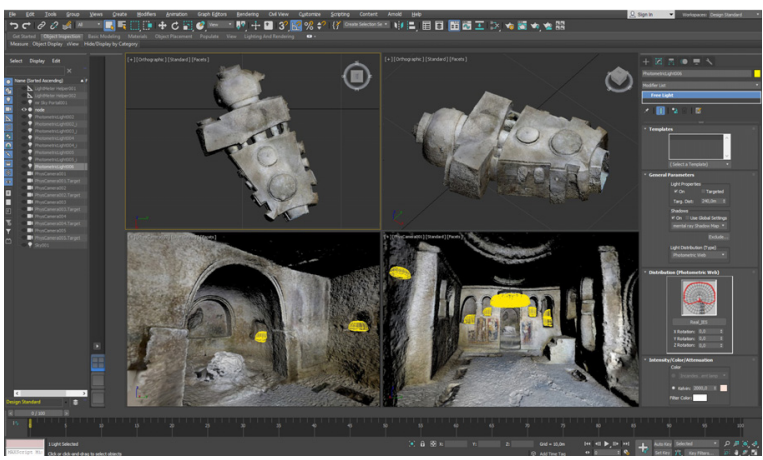

Figure 5: Sw 3D Studio Max. Hypothesis of artificial illumination.
Virtual prototypes of medieval lighting systems (chandeliers and oil lamps) were created in 3D studio Max to study lighting scenarios. The technical data (illuminance and luminance), obtained from the simulations, gave further indications for the definition of lighting scenarios of that period.

Finally, the virtual model was imported into 3DHop (3D Heritage Online Presenter) an open-source visualisation software package developed by the ISTI institute of the CNR. Thus, it is measurable and viewable on line. Moreover, some other contents (texts, images, multimedia forms about lighting scenarios) are embed and linked to interactive hotspots. In this way, it is possible to appreciate the artefact on line also in relation to the medieval lighting system.

\section{RESULS AND DISCUSSION}

The combined use of the survey with laser scanner and digita photogrammetry has resulted in a metrically reliable threedimensional model with a high quality texture (Remondino and El-Hakim, 2006).

Thus, it was possible to create photo-realistic scenarios of natural and artificial lighting systems similar to the original ones.

Furthermore, the use of the two methods allowed us to have a 3D model consisting of a light mesh and easily managed by multiple software (Lo Brutto and Spera, 2011).

The lighting analysis results of the Church of Santa Barbara in the medieval period started from the study of the internal conditions of natural lighting in different periods of the year and times of the day. The variability of natural light was analysed by importing the model into the 3D studio Max software that allows setting the location (Matera), the day and the time to analyse through the Sunlight and Daylight systems. In particular, the IES Sun and IES Sky lights were used with the mental ray Sun \& Sky solution in order to have photometric daylight related to sun position.

The results of the simulations were on two levels:

1. Photo-realistic scenarios created with the mental ray Renderer that reproduces the visual effect of the system of illuminations, both natural and artificial, according to historical and cultural reconstructions through the radiosity algorithm.

2. Analysis of the scientific data through the function of the lightmeter and the pseudo-colour exposure control in 3D studio max. The lightmeter function allows the level of illuminance to be measured on fixed planes (horizontal and vertical) in natural, artificial and combined lighting conditions and, at the same time, to be shown according to a coloured spectrum bar. The pseudo-colour exposure control transforms the brightness of the scene in terms of progressive luminance in the following order: blue, cyan, green, yellow, orange and red or in grey scale. The coloured image indicates the amount of lighting that returns to an eye that sees the scene in the position of the virtual camera.

Through the photorealistic scenarios, it was possible to analyse daylighting throughout different seasons and times as well as to verify the interpretative hypotheses on the position and the type of chandelier and oil lamps that also have to be analysed in terms of lighting performance levels. The church 
results scarcely illuminated by natural light (Figure 6) and in a non-uniform way.
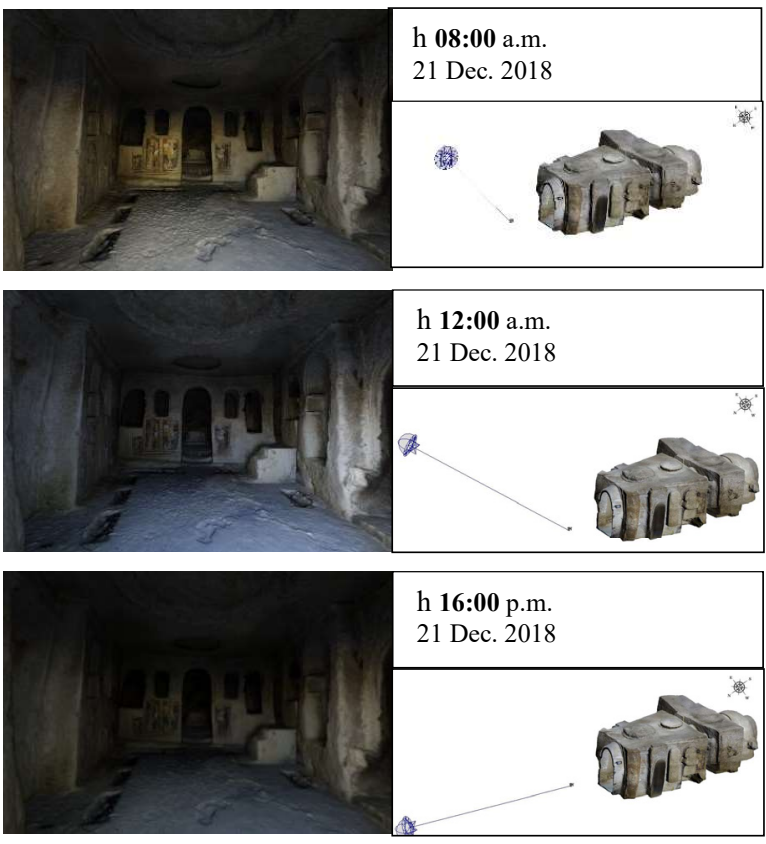

Figure 6: 3D Studio Max Sw. Photorealistic renderings of the nave during the winter solstice.

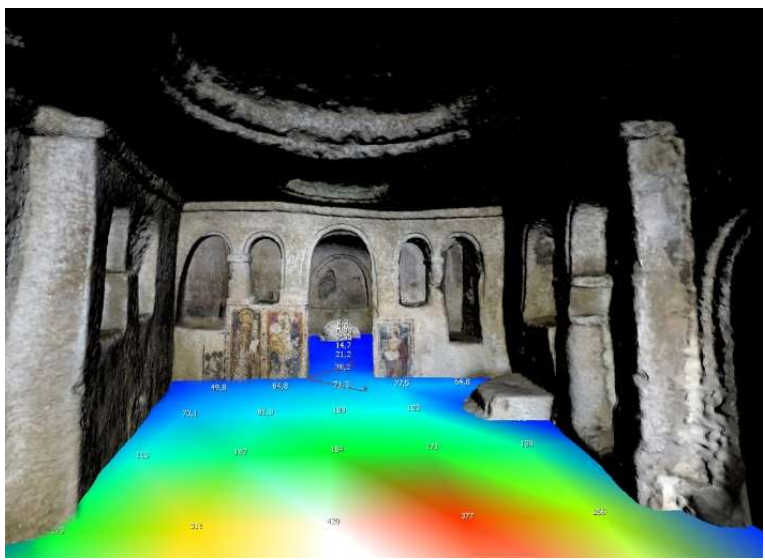

Figure 7: 3D Studio Max Sw. Lightmeter for lighting analisys. Daylight in the nave -h 12.00 - Date: 21 June 2018

On the horizontal plane $(\mathrm{h}=1 \mathrm{~m})$ the area near the entrance at 12:00 (with the maximum sky brightness) reaches along the axis of the Church the value of 429 lux in the summer solstice (Figure 7) and 330 lux in the winter solstice (Figure 8). Whereas, the illuminance level is reduced considerably in the nave at 6 meters from the entrance to the value of 39.2 and 25.0 lux respectively.

The light conditions are significantly reduced at very low values (14.7-10.8 lux) in the bema and the apse (apse) (7.73-0.03 lux) both in summer and in winter due to the presence of a single opening on the front and to the depth of the church, which determine a considerable reduction of natural light.

Therefore, the illuminance levels in the apse and in the bema are not very influenced by the variation of the daylight (Figure 9).
Also the analysis of the luminance distribution in false colours under the same natural lighting conditions shows that the area behind is very dark $(<16 \mathrm{~cd} / \mathrm{m} 2)$ as well as the whole environment (Figure 10).

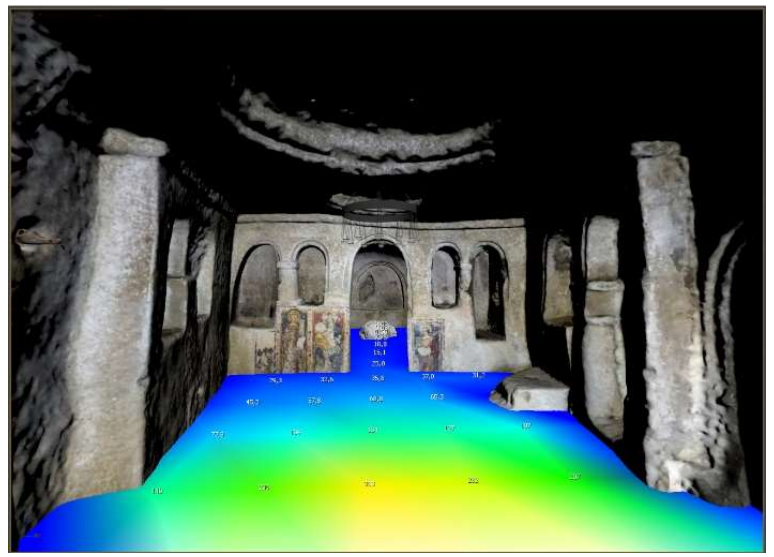

Figure 8: 3D Studio Max Sw, Lightmeter for lighting analysis. Daylight in the nave -h 12.00 - Date: 21 Dec. 2018
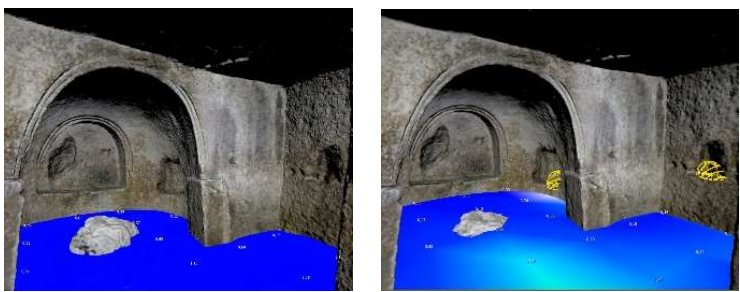

a b

Figure 9: 3D Studio Max Sw, Lightmeter for lighting analysis Natural (a) and artificial light (b) in the apse - h 08.00 a.m. Date: 21 Dec. 2018

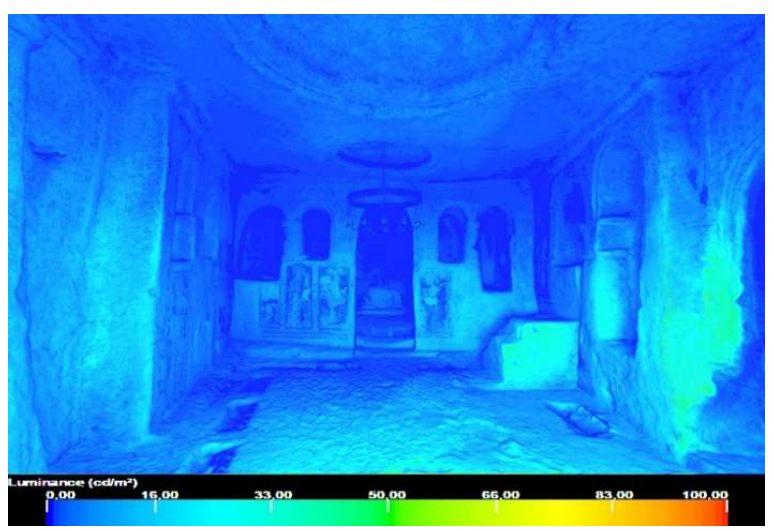

Figure 10: 3D Studio Max Sw. Pseudo Color Exposure Control - h 08.00 a.m. - Date: 21 Dec. 2018

These studies make evident the need for lighting systems in the rupestrian church. Some one-nozzle clay oil lamps with medium size reservoir were placed in the 3D studio Max model, because, after Roman times, their use was continued even if with a more elongated nozzle. In each oil lamp, the photometric features of the flame (produced by a cotton wick) were inserted as a "Free 
Light" in the 3D studio Max through a file with the extension .IES considering a low colour temperature $\left(1500^{\circ} \mathrm{K}\right)$. This file IES produces a distribution of light based on the photometric characteristics (Figure 5) obtained through the real-ies software and by similar studies (Moullou, 2013). In addition, it was placed a chandelier, whose position is both defined by historical interpretations of architectural signs and detected by lighting considerations. A three-dimensional model of a chandelier was reconstructed taking into account the historical documentation (Dell'Aquila, 2018) for the church of "Cristo alla Selva" in Matera (Figure 11), whose chandelier was taken from examples of polykandela attested in the monasteries of Athos. Moreover, the same file with the extension.IES was inserted for each of 12 glass little cups which are reservoirs of oil for lighting by flame.
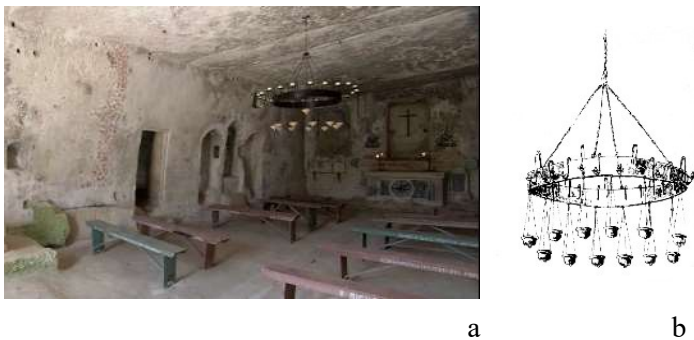

Figure 11: "Cristo alla Selva" Church, Matera (a). Metal chandelier to hang from the ceiling composed of chains and a series of 12 small cups used as oil containers (b).

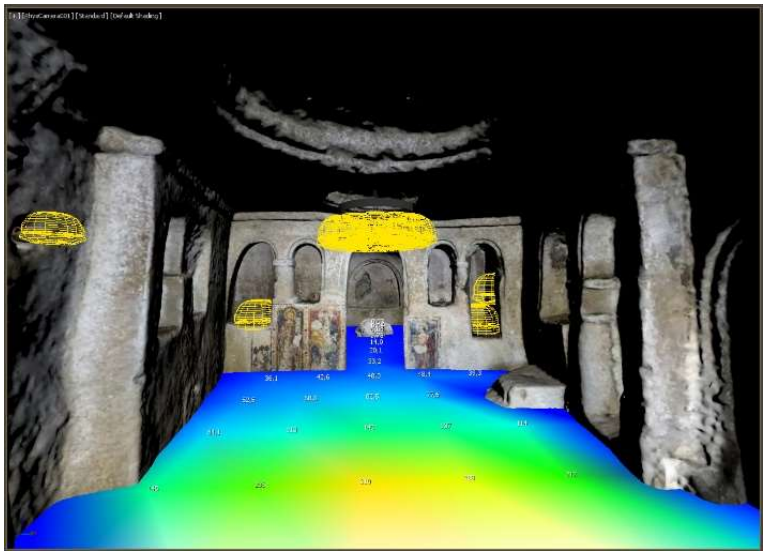

Figure 12: 3D Studio Max Sw. Lightmeter for lighting analysis. Natural and artificial light in the nave. h $08.00 \mathrm{a} . \mathrm{m}$. - Date: 21 June 2018

The position of the hypothesized chandelier (distance from the entrance equal to 5 meters) allows increasing the level of illumination in the central area of the whole church (Figure 12) and on the frontal wall paintings (Figure 13) and on the lateral side (Figure 14). In fact, even if it is decentralized in relation to the nave, it is moved towards the bema where there are only niches for lamps and the apse where there is the altar where portable lights could be placed to increase the level of illumination.

Due to their photometric curve and luminous intensity, the oil nozzled lamps do not allow having an intense illuminance that, even if it is distributed mainly upwards, its effect is reduced to the closely surrounding zone as the photorealistic render images of bema and apse show (Figure 15-16).
Instead, a chandelier distributes the light also vertically downwards and increases the mean cylindrical illuminance (Ez) and consequently the visual perception of the surrounding space. Surely, in the church during use we did not reach the levels of illuminance we are used to today in compliance with the UNI 12464-1: 2011 standards for places of public assembly. The light above all had a symbolic value during the liturgy, not just for a particular visual task that, in the medieval period, did not include reading activity for churchgoers in the medieval age.

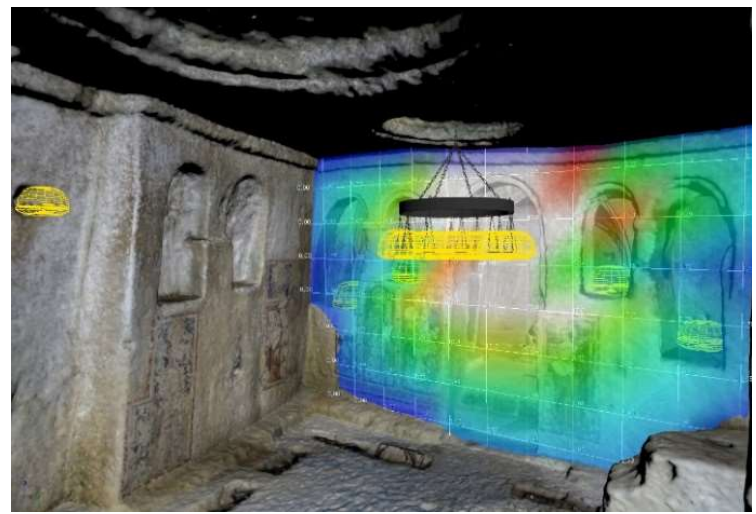

Figure 13. 3D Studio Max Sw. Lightmeter for lighting analysis. Natural and artificial lighting on the front wall.

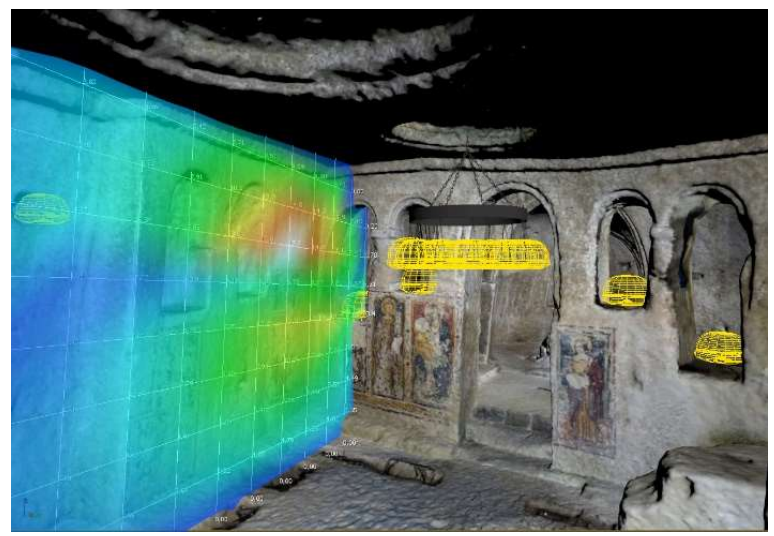

Figure 14: 3D Studio Max Sw. Lightmeter for lighting analysis. Natural and artificial lighting on the side wall.

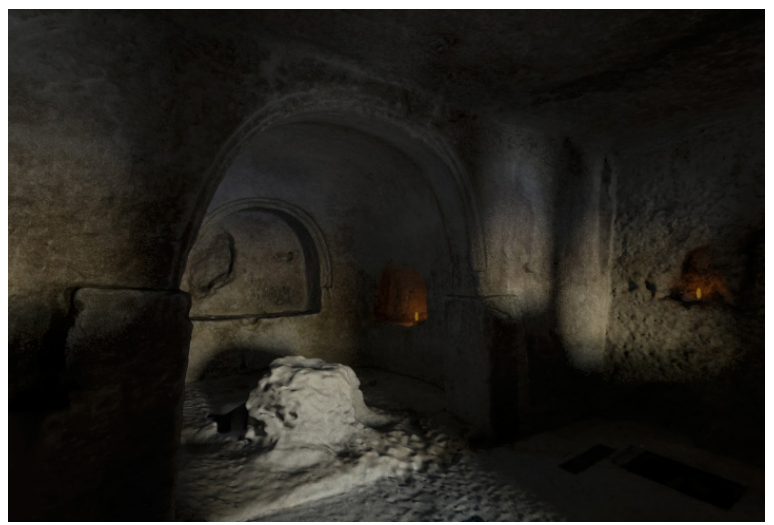

Figure 15: 3D Studio Max Sw. Photorealistic render of the apse with combined lighting. h 17.00 p.m.-Date: 21 Dec. 2018 


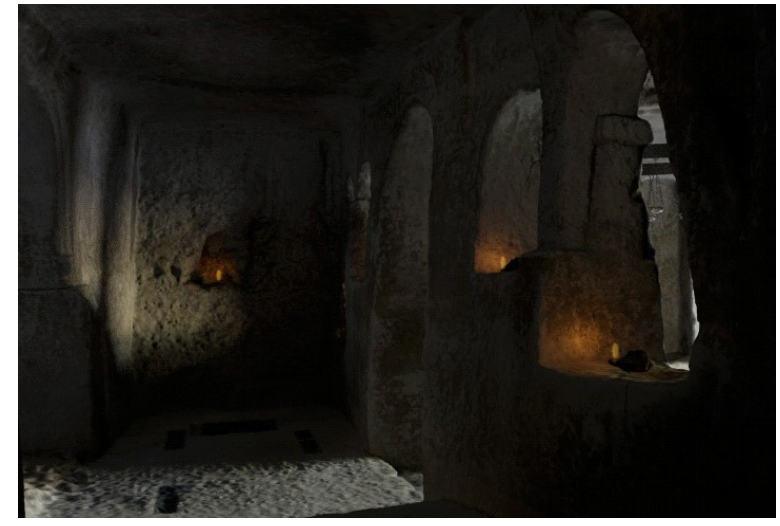

Figure 16: 3D Studio Max Sw. Photorealistic render of the bema with combined lighting. h17.00 p.m.-Date: 21 Dec.2018

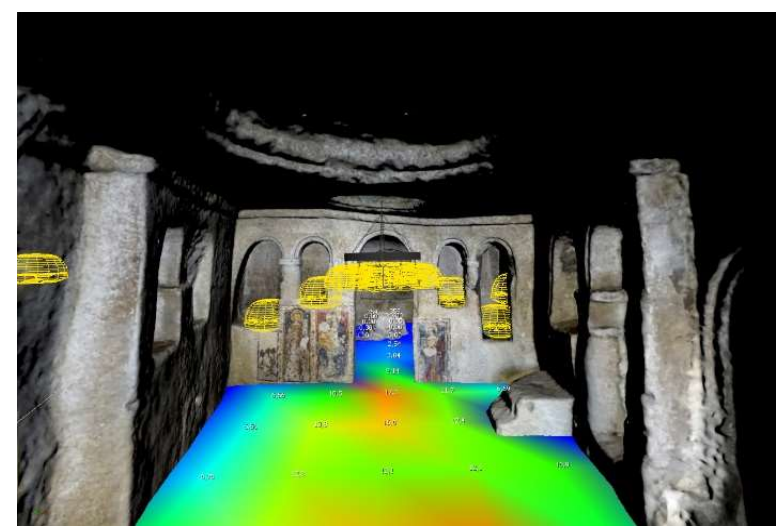

Figure 17: 3D Studio Max Sw. Lightmeter for lighting analysis. Natural and artificial lighting in the nave. h 08.00 p.m. - Date: 21 Dec.2018

As shown in Figure 17 the artificial light distribution of the chandelier is more concentrated in the central part of the Church and penetrates in the area of the bema and of the apse also when natural lighting is scarce.This is a proof that this must have been the position of the chandelier.

In addition to the previous model of chandelier with reference to other historical sources (Olçay, 2001; Acara and Olcay, 1998) and findings (glass lamps found in an excavation in Abila Jordan), another chandelier with 6 glass cups was considered for the lighting simulations.

The second hypothesis considers that for smaller churches the number of little cups often decreased from 12 (symbols of the apostles or signs of the Zodiac) to 6 . Anyway, the differences in terms of lux are not so evident (about 5-10 lux) but this possible reduction can be attributed to a matter of church dimensions and to the availability of oil for lighting, which in the area of Matera usually came from the lentisk (Pistacia lentiscus).

The comparison of the photo-realistic images (Figures 18-19) and the lighting analysis with the two different chandeliers shows that both hypotheses are plausible. The image on the luminance distribution (Figure 20) demonstrates a particular increase towards the ceiling near the chandelier due to the photometric curve of the flames, which projects the light mainly upwards.

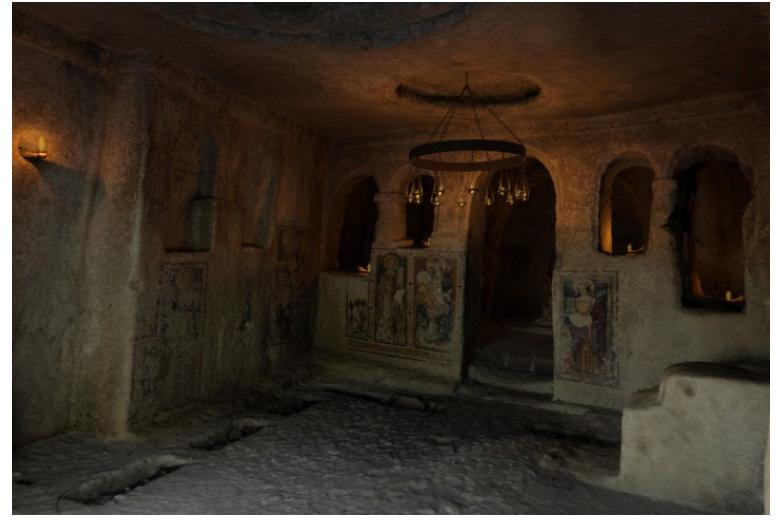

Figure 18: 3D Studio Max Sw. Photorealistic render of the nave with the chandelier with 12 glass little cups. h 17:00 p.m. Date: 21 Dec. 2018

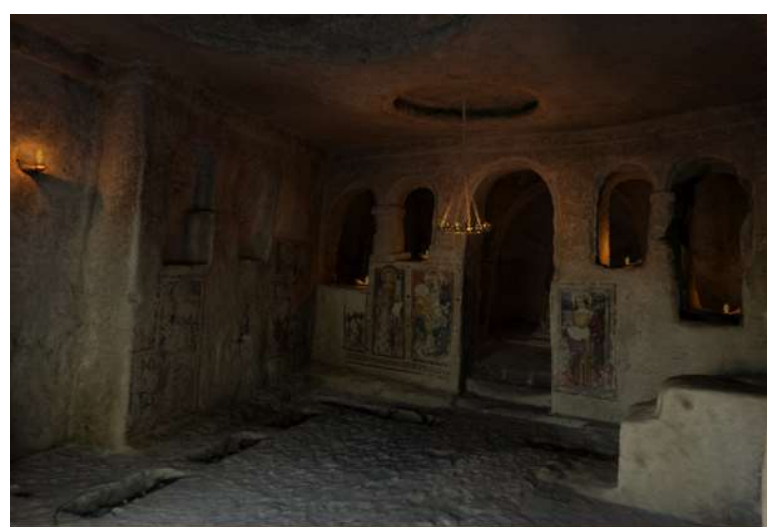

Figure 19: 3D Studio Max Sw. Photorealistic render of the nave with the chandelier with 6 glass little cups. h 17.00 p.m. - Date: 21 Dec. 2018

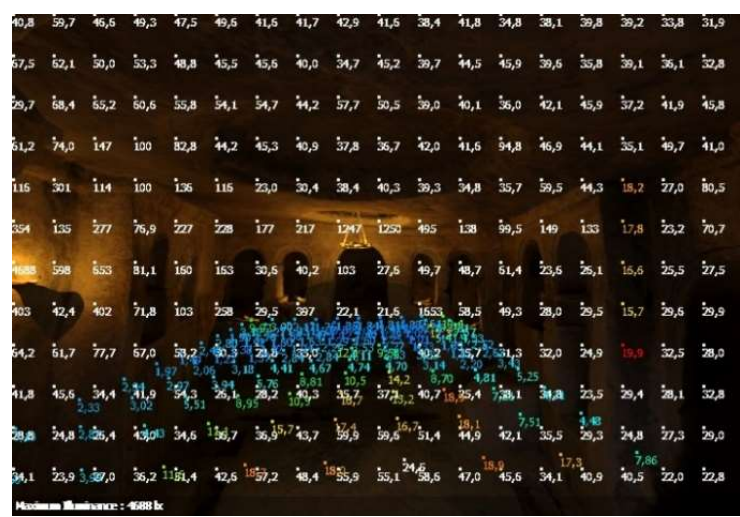

Figure 20: Luminance distribution-h 8 del 21.12.2018

Finally, the model was imported in 3D HOP and so it is measurable online by measurement tools (Figure 21).

Moreover, in this model it was possible to insert interactive hotspots collecting the different levels of results (historical documentation and interpretations and detailed lighting analysis) and to make them accessible on the internet (Figure 22, http://demo.ba.itc.cnr.it/3D/matera/chiesa-santa-barbara.html). 


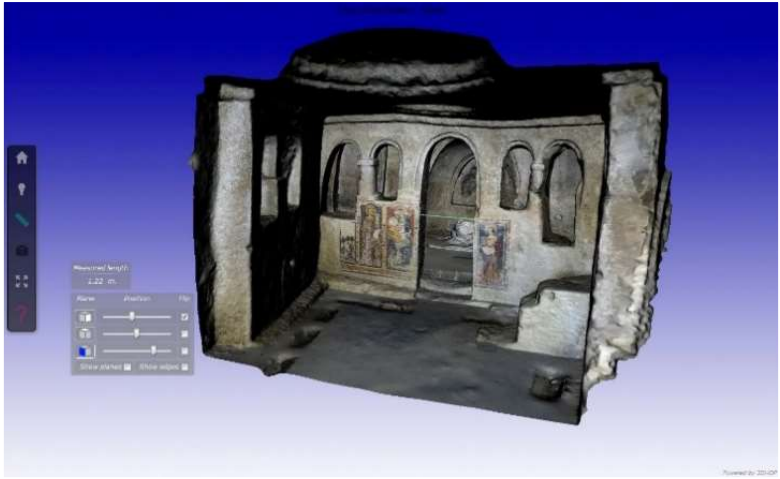

Figure 21: 3DHop Sw. Cross section with measured length (http://demo.ba.itc.cnr.it/3D/matera/chiesa-santa-barbara.html).

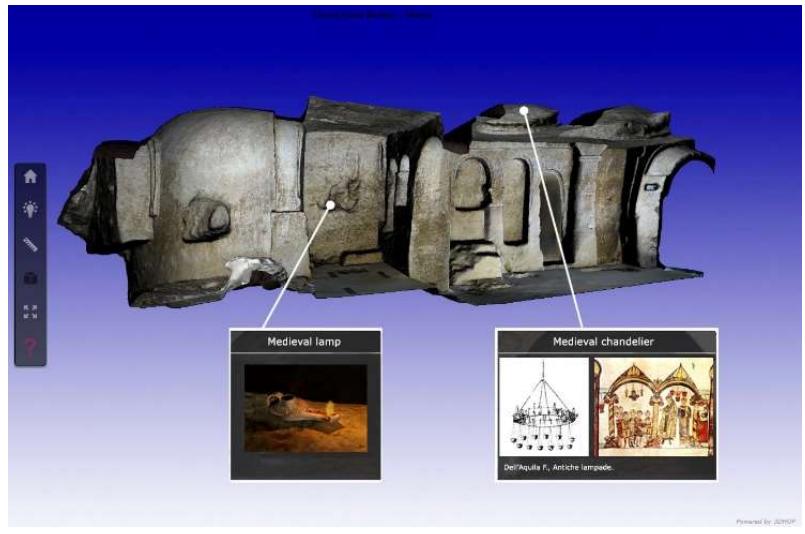

Figure 22: 3DHop Sw. Longitudinal section with hotspots.

\section{CONCLUSIONS}

This method integrates survey, 3D representation, lighting study and online visualization of a historical-cultural artefact and contributes to enhance and promote cultural heritage with a potentially huge audience over the internet.

The simulations of light conditions, deriving from scientific studies, through high-definition 3D reconstruction, offer an emotional perception of historical illumination effects that can be proposed for current fruition. This is promising thanks to the possible use of dimming controls for lighting (e.g. for led systems) to balance the new quality Illuminance criteria with historical re-construction needs.

\section{ACKNOWLEDGEMENTS}

The authors would like to acknowledge Capotorto Salvatore (ITC-CNR, Bari) for the photogrammetric survey of Santa Barbara Church and web publication through 3D Hop software. The above study was developed as part of an ongoing PRIN research entitled "Luce Crea Luce" by the working group made up of researchers from the University of Urbino, Bari, Rome, Florence and Construction Technologies Institute (ITC-CNR, Bari)

\section{REFERENCES}

Acara, M., Olcay, B. Y., 1998, Bizans Döneminde Aydinlatma Diizeni ve Demre Aziz Nikolaos Kilisesi 'nde Kullanilan Aydinlatma Gereçleri, Adalya, 2, p. 263.

Akca, D., 2012, 3D modeling of cultural heritage objects with a structured light system. In: Mediterranean Archaeology and Archaeometry, Vol. 12, No 1, pp.139-152.

Bouras L., Parani M.G. (eds.), Lighting in Early Byzantium, Washington 2008

Dell'Aquila, F., 2018 Antiche lampade, http://www.pugliaindifesa.org/files/Lampade.pdf (Last accessed on December 2018).

Lo Brutto, M., Spera, M.G., Image-based and range-based 3D modelling of archaeological cultural heritage: the Telamon of the temple of Olympian Zeus in Agrigento Italy), International Archives of the photogrammetry, remote sensing and spatial information sciences, Trento: ISPRS, pp. 515-522.

Yelda Olçay, B., 2001. Lighting Methods in the Byzantine Period and Findings of Glass Lamps in Anatolia, Journal of Glass Studies, 43, pp. 77-87.

Melendo, J. M. A., Lainez, J. M. C., Cunill, I. R., 2018. Lighting Features in Historical Buildings: Scientific Analysis of the Church of Saint Louis of the Frenchmen in Sevilla. In: Sustainability Vol. 10(9):3352, DOI: 10.3390/su10093352

Merlo, F., Fantini, G., Lavoratti, A., Aliperta, J., L. Lopez Hernandez. Texturing e ottimizzazione dei modelli digitali reality based: la chiesa della Compañía de Jesús. In: Rivista digitale DisegnareCon. Ottobre 2013.

Moullou, D., 2013. Lighting Night-Time activities in Antiquity. In: M.E. Micheli - A. Santucci (a cura di), Lumina, Atti del convegno internazionale - Urbino 5-6 giugno 2013 (Pisa 2015), pp.199-212.

Moullou D., Madias E.N.D., Doulos L.T.,.Bouroussis C.A , Topalis F.V., 2012. Lighting in Antiquity. In: M. Kostic (ed.), Proceedings of 5th Balkan Light International Conference Belgrade 3-6 October 2012 (Belgrade 2012) pp. 237-244.

Moullou, D., Bisketzis, N., Tselonis C., Egglezos, D., Filippopoulou, O., Topalis, F.V., 2010. Methods and Tools for the Study of Artificial Illumination in Antiquity. In: N. Zacharias (ed.), Proceedings of the 2nd Archaeological Research and New Technologies Conference - Kalamata 21-23 October 2010 (Kalamata 2012) pp.107-114.

Papadopoulos C. and Earl G. P., 2009. Structural and Lighting Models for the Minoan Cemetery at Phourni, Crete. In: K. Debattista, C. Perlingieri, D. Pitzalis, and S. Spina (Editors), The 10th International Symposium on Virtual Reality, Archaeology and Cultural Heritage VAST, pp.1-8.

Remondino, F., El-Hakim, S., 2006. Image-based 3D modelling: a review, The Photogrammetric Record, Vol. 21 (115), pp. 269291. https://doi.org/10.1111/j.1477-9730.2006.00383.x

Santucci A., Lassandro P., Zonno M., 2018. Lighting a funerary interior. The Roman Tomb N83 at Cyrene in a 3D perspective". In: Proceedings of 19th International Congress of Classical Archaeology, Cologne/Bonn, 22 - 26 May 2018. 